\title{
An Exploratory Evaluation Of A Treatment Mall At A State Psychiatric Hospital
}

Aja N. Matthews, MSW, University of Maine, USA

Blake Beecher, Ph.D., Eastern Washington University, USA

Pamina J. Hofer, Ph.D., USA

Robert A Short, Ph.D., USA

\begin{abstract}
The Treatment Mall is a model of inpatient psychosocial treatment provided to adults with severe mental illness to deliver recovery-oriented, evidenced-based treatment and has been implemented in state mental hospitals across the United States. The present study is an exploratory evaluation of a recently implemented Treatment Mall in a state mental hospital. To evaluate this program, the experiences of clients $(N=28)$, staff $(N=32)$, and administrators $(N=5)$ were compiled using a quantitative questionnaire and focused on empowerment, skill development, and satisfaction. Additionally, data from the hospital database $(N=183)$ were extracted and analyzed by comparing frequencies of occurrence 90 days before and 90 days after Treatment Mall implementation. The findings indicate that clients reported learning skills and were satisfied with how they were treated at the Treatment Mall. Female clients and staff viewed independent living and recovery possibilities significantly more positively than male clients and staff. Hospital performance indicators showed no significant changes pre to post implementation.
\end{abstract}

Key Words: Mental Health; Psychosocial Rehabilitation; State Psychiatric Hospitals; Empowerment; Treatment Mall; Skill Development

\section{INTRODUCTION}

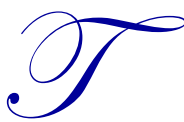

he revolving door phenomenon at state psychiatric hospitals is more prominent over the past few decades as a result of decreased lengths of stay and continued effects of deinstitutionalization (Langdon, Yaguez, Brown, \& Hope, 2001). Increased awareness of the interconnectedness of the hospital and the community brings with it the hospital's responsibility to take an active role in reducing rates of relapse and rehospitalization of individual's with serious mental illness. Empirical evidence indicates that this connection significantly increases the individuals' ability to maintain social, vocational, and clinical functioning (Boyer, McAlpine, Pottick, \& Olfson, 2000; Vigod et al., 2013). Treatment Malls are now used in many states as a model to provide active psychosocial treatment in state psychiatric hospitals. The present study will evaluate the changes in hospital performance pre and post implementation of a Treatment Mall in a state psychiatric hospital in the Pacific Northwest.

\section{Recovery and Psychosocial Rehabilitation}

Treatment malls are closely related to the recovery and psychosocial rehabilitation movements in mental health (Bartholomew \& Cook, 2013). Recovery for individuals in a state hospital is likely to be improved by treatment approaches that emphasize a collaborative treatment relationship, individualized treatment, hope, empowerment, self-responsibility, and meaningful roles (Chinman, Rosenheck, \& Lam, 2000; Olfson et al., 2000, Ragins \& Pollack, 2013). Family involvement in treatment, responsible use of medication, and collaborative transitions from the hospital to the community setting may also play a role in recovery from mental illnesses (Boyer et al., 2000; Vigod et al., 2013). Psychosocial rehabilitation is frequently used to facilitate an individual's recovery by utilizing a comprehensive approach in the provision of vocational, independent living, and social/recreational services (Thorn, Bamburg, \& Pittman, 2007). Psychosocial rehabilitation contrasts to the traditional custodial care 
model that has been common in state hospitals for decades, and has the goals of identifying the deficits in an individual's repertoire of skills and improving them with the ultimate goal being the reduction or elimination of barriers to successful community living (Longo, Marsh-Williams, \& Tate, 2002).

Three major principles underlying psychosocial rehabilitation are empowerment, competence, and recovery (Stromwall \& Hurdle, 2003). Empowerment involves individuals making choices about their treatment with the benefit of gaining a positive sense of self. Through empowerment, individuals become increasingly independent as they gain skills and change from being passive recipients of treatment, as in the medical model, to being active managers of their treatment and their own lives and social networks. In psychosocial rehabilitation, competence refers to a focus on strengths and skills, rather than symptoms and deficits. Recovery, a term long used in substance abuse treatment, is "a process of change through which individuals improve their health and wellness, live a selfdirected life, and strive to reach their full potential" (SAMHSA, 2012). The concept of recovery from mental illness sets an expectation for improvement, rather than life-long chronicity (Stromwall \& Hurdle, 2003), and the goal for the individual to build a life worth living, rather than merely symptom reduction (Carpenter, 2002).

\section{Treatment Mall}

The term Treatment Mall has been used to describe the physical space in which psychosocial rehabilitation programming occurs in a psychiatric hospital where clients and staff meet for a significant portion of each day (Ballard, 2008). Treatment Mall programming is provided by a multidisciplinary team of staff in off-ward, centralized, school-like settings located away from a hospital's residential wards, where clients receive treatment, education, skills training, and support (Webster et al., 2009). "The treatment mall was developed specifically to deliver recovery-oriented, individualized, evidenced-based, psychiatric rehabilitation in a state psychiatric hospital" (Bartholomew \& Cook, 2013, p. 181). The client's individual Treatment Mall schedules are a result of a collaborative process between the client and his or her treatment team. The entire ward functions including staff duties are moved to the Treatment Mall during a significant part of every week day (Webster et al., 2009). Many offward Treatment Malls bring hospitalized individuals and community members into contact with each other on a daily basis (Carpenter, 2002). This serves not only to increase the social opportunities and skills of the hospitalized individual, but also to expose community members to individuals with mental illnesses and potentially lessen the stigma of mental illness. Furthermore, Treatment Malls often provide community services, such as a beauty salons, banks, and shops, which can prepare individuals to interact with similar businesses in the community (Carpenter, 2002). The treatment mall in the present study possessed the previous described characteristics except for community engagement and the provision of community services.

Another intended goal of the psychosocial rehabilitation Treatment Mall approach at state hospitals is to increase the involvement in treatment of hospitalized individuals with serious mental illnesses (Bopp, Ribble, Cassidy, \& Markoff, 1996). Several researchers have found a positive correlation between involvement in treatment and functioning (Brekke, Ansel, Long, \& Weinstein, 1999; Coleman \& Paul, 2001; Dietzen \& Bond, 1993; Sands \& Cnaan, 1994; Snowden \& Clancy, 1990).

To date, there is very limited research on the Treatment Mall model beyond satisfaction outcomes. According to Bartholomew \& Cook; "There are no methodologically rigorous outcome studies published on the effects of inpatient treatment malls" (2013 p. 183). Only one study was found that evaluated Treatment Mall outcomes. Longo et. al. (2002) reported the inpatient recidivism rate decreased by $9 \%$ within 6 months of Treatment Mall implementation and seclusion events were reduced by 50\%. However, these findings were added at the end of an implementation article and did not include any methodological information. The literature has not yet addressed the impact of gender, age, time at institution, and other demographic factors as they relate to the Treatment Mall.

The current study assesses the implementation of a Treatment Mall in a state psychiatric hospital in the Pacific Northwest. It addresses the question: "Have there been changes in the hospital's performance as perceived by clients, staff, and administrators and reflected by hospital performance indicators since the Treatment Mall program implementation?" There were two parts to this study; part one involved anonymous surveys of clients and staff using nine Likert scaled questions. Themes investigated include: (a) clients' empowerment by attending the Treatment Mall, (b) clients' skill development within the Treatment Mall, and (c) respondents' satisfaction with the 
Treatment Mall. The second part of the study used archival data from the hospital database, including data about elopements, assaults by clients, the use of physical restraints and seclusions, and pro re nata (PRN) medications as indicators of hospital performance. The frequencies of these indicators were compared for three month periods before and after implementation of the Treatment Mall program. The results of this study provide an initial impression of immediate outcomes associated with the Treatment Mall program.

\section{METHODS}

This study is a preliminary evaluation of the Treatment Mall at one psychiatric hospital and is exploratory in nature. As this study was conceptualized as a first step in the evaluation process and a way for the hospital to receive initial feedback, relatively short data collection time frames were utilized.

The main objective of the study was to investigate Treatment Mall outcomes from the perspectives of multiple constituency groups. There were three groups of participants recruited into the first part of the study. The first were adult clients in the hospital attending the Treatment Mall at least 4 days per week for 3-5 hours per day for the past 90 days. The second were hospital staff including nurses, social workers, mental health technicians, occupational therapists, physical therapists, psychiatrists, and psychologists. The third group was administrators in the hospital and consisted of a director from each of the previously stated professional disciplines. Only staff and administrators who were involved in the Treatment Mall at some level were invited to participate in the survey.

Data for the second part of the study were from clients who participated in the Treatment Mall during the study period. They were included if they were present both three months before and three months after the implementation of the Treatment Mall. An additional requirement was that the clients came from non-forensic wards (as mandated by the institutional review board).

The content of the survey instruments developed for the study were based on meetings with hospital staff and evaluation of the hospital mission statement. Similar surveys were developed for administrators, staff, and clients, and contained the categories of empowerment, satisfaction of the Treatment Mall, and skill development (See Appendix A). Scale reliability was calculated using Cronbach's alpha (=.89) and indicated adequate internal consistency. Surveys were administered three months after implementation of the Treatment Mall.

Data were extracted from the hospital database for PRN medication use, seclusions, restraints, and number of elopements for three months prior to implementation of the Treatment Mall and post implementation data were from three months after implementation.

The study included a total of 67 adult participants (over age 18). All clients on the adult inpatient wards were invited to participate in a study. Upon agreeing to learn more about the study, she/he was asked to participate in the study using a structured document that explained what the study was about and was subsequently asked to read and sign the Informed Consent document. To ensure the anonymity of their responses, numbers were assigned to the interview packet, which was kept separate from Informed Consent documents, and completed surveys were returned to a locked box available on the ward. To recruit staff and administrators, an email was delivered introducing the study and announced the dates of the study. Surveys were then delivered along with cover letters explaining the study. To ensure the anonymity of responses, numbers were assigned to the interview packet, and individuals were asked to keep the cover letter. Participants were asked to complete the surveys and return the surveys to their wards or to other locations in the hospital in a locked collection box. Data were extracted from the hospital database records for the selected hospital wards and study dates. All personal identifiers were excluded from the study data. The study was approved by the State Institutional Review Board. 


\section{FINDINGS}

\section{Survey Data}

The response rate to the survey was $32 \%$ for staff $(\mathrm{N}=32)$, and $24 \%$ for administration $(\mathrm{N}=6)$. Only the clients interested in the study completed a survey; 28 out of the 60 eligible clients responded for a $47 \%$ response rate (See Table 1).

Means of survey item scores (Table 2) indicate that clients agreed somewhat with the survey item statements and agreed most with items $4(\bar{x}=5.6), 7(\bar{x}=5.5)$, and $9(\bar{x}=5.5)$. These items address client views about learning and satisfaction with the Treatment Mall. Staff agreed most with survey items $4(\bar{x}=5.8), 7(\bar{x}=$ $5.7)$, and $8(\bar{x}=6.8)$ related to the Treatment Mall's benefits to clients. Administrators rated survey items $2(\bar{x}=$ $6.7)$, and $8(\bar{x}=6.7)$ highest, which addressed how clients were involved in treatment teams and took an active role in their recovery.

A one-way analysis of variance was conducted to evaluate the relationship between groups (stakeholders) and the dependent variables (questionnaire items). The ANOVA was significant for item 2 (team) $\{\mathrm{F}(2,62)=3.53$, $\mathrm{p}=.035\}$ and item 8 (role) $\{\mathrm{F}(2,64)=14.20, \mathrm{p}<.000\}$. Follow-up tests were conducted to evaluate pair wise differences among the means. Because the groups had unequal variances, post hoc comparisons were performed using Dunnett's C test. Administrators rated item 2, "Members of my treatment team treat me as a team member", significantly higher than both staff and clients. Although item 8 was also significant, this finding may not be meaningful as the staff and administrators answered a slightly different question.

ANOVA tests were also performed to assess the relationship between clients, staff and administration survey item responses by gender. Because there were few administrator responses, staff and administration responses were merged into one category for the analyses. Significant differences by gender were found on the survey item of recovery with both clients and staff. Female clients and staff viewed item 7 , related to recovery, significantly more positively than their male counterparts $\{\mathrm{F}(1,28)=4.28, \mathrm{p}=.05\}$ and $\{\mathrm{F}(1,34)=5.93$, $\mathrm{p}=.02\}$, respectively. Female clients also rated item 5 , independence $\{\mathrm{F}(1,28)=3.65, \mathrm{p}=.066\}$, and item 6 , community $\{\mathrm{F}$ $(1,28)=3.06, p=.09\}$, both relating to being able to function independently in the community, more positively than their male counterparts, with results that approached significance. Similar to female clients, female staff rated item 5 , independence, significantly more positively than their male counterparts $\{F(1,34)=8.06, p=.008\}$.

Correlation coefficients were computed among the nine survey items with age and how long the participant has been at the hospital. Using the Bonferroni approach to control for Type I error rate across the 11 correlations, a $\rho$-value of less than $.005(05 / 10=.005)$ was required for significance. The length of time that staff had worked at the hospital was inversely correlated with the variable of independence $-.44, p=.008$, which approached significance. This indicates the longer staff worked at the hospital, the less likely they were to be optimistic about a client's ability to become independent. No other correlations were significant in both the client or staff/administrator correlations.

\section{Hospital Data}

Data used to evaluate hospital performance indicators three months before and after the Treatment Mall implementation were from adult psychiatric wards $(\mathrm{N}=183)$ actively participating in the Treatment Mall. The mean age for the clients was 40 (SD 12); 63\% were male and 37\% female, $72 \%$ were never married, 19\% were divorced, and $7 \%$ were currently married. Eighty-five percent of the clients were Caucasian, $4.4 \%$ Native American, $4 \%$ African American, 3\% Hispanic, 1\% Asian or Pacific Islander, and 2\% other. Client diagnoses included Schizophrenia (62.8\%), mood disorders (31.1\%), and other diagnoses (6.1\%). Fifty-five percent of clients also had a past or current substance abuse diagnosis.

The McNemar Chi Square test was used to test whether introducing the Treatment Mall reduced negative incidents pre and post implementation (Table 3). The variables analyzed pre and post Treatment Mall included: PRN medications (benzodiazepines, hypnotics, antipsychotics, and pain), elopements, assaults client to client, assaults client to staff, seclusions, and restraints. None of the McNemar tests were significant between pre and post 
Treatment Mall implementation (Table 3). Assaults client to staff $(\mathrm{p}=.125)$ was the variable closest to significance, with the number of clients who had assaults decreasing from 5 to 1 .

\section{DISCUSSION}

One purpose of this study was to help hospital personnel better understand how the implementation of the Treatment Mall affected clients at a state psychiatric hospital. A positive finding was that clients somewhat agreed with all of the items on the survey as indicated by the mean of each survey item. For most items (Table 2), staff did not view the Treatment Mall more positively than clients (except for item 8), which is interesting as one would assume staff have a greater investment in the program.

A one-way analysis of variance showed administrators viewed item 2 (team) significantly different from both staff and clients. Administrators may have reported what should be occurring, while staff and clients reported what is actually happening. Female clients and staff (combined with administrators) viewed recovery (item 7) and independence (item 5) significantly more positively than the male clients and staff. Female staff also viewed independence after discharge (item 6) significantly more positively than male staff. These findings indicate that women view recovery and community independence for clients as more likely to occur and much more positively than the male participants. There are many possible reasons for this finding. It may be that a small group of male and/or female clients and staff socialize with each other and thus influence the views of the group. This may also be reflected by a specific group of male clients who have very severe symptoms and limited views of independence and recovery. Staff members frequently work with clients of the same gender, so it is possible that this group of clients may have also influenced staff member views.

Correlations among age and length of stay/time employed at the hospital with the survey item scores indicated that the longer that staff worked at the hospital the more they reported negative views about independence for clients. Because staff age was not significantly correlated with any variables, we surmise that views about client independence were influenced by how long they worked at the hospital, not the age of staff members. This correlation also indicated that staff who worked at the hospital for a shorter period of time had more positive views about client independence. This may indicate that socialization occurred in the hospital setting which influenced staff views on the capacities of clients to live independent lives. A state mental hospital is also a setting in which clients are likely to exhibit the most severe and debilitating end of the continuum of their mental illness symptoms, and as the symptoms improve, they are likely discharged from the hospital. It may be that the longer staff are working with clients who are experiencing their most debilitating symptoms, the more they believe in the chronicity of symptoms and the client's inability to function independently.

Client's age or how long they were currently hospitalized did not significantly correlate with any of the survey items, indicating that clients who had been hospitalized for a longer length of time had similar views about their ability to recover, be independent in the community, and their satisfaction with the Treatment Mall. This was a surprising finding, as many individuals with mental illness who are in institutional settings over longer periods of time tend to become socialized into limiting their independence and capabilities (Chow \& Priebe, 2013).

No statistical tests were significant in comparing client outcomes 3 months before and 3 months after Treatment Mall implementation. It is likely that changes in the culture and practices in state hospital settings take time and considerable supervision, support, and staff buy-in. The implementation of a new program regardless of how innovative or well received will not likely have immediate change effects on entrenched cultures and practices.

There are several limitations in the present study. The low staff and administrator response rate may bias the results reported, and the timeframe of three months before and three months after the Treatment Mall started was likely too short a timeframe to reflect Treatment Mall effectiveness. Floor effects of some variables (i.e. only 1 elopement during baseline period) make it impossible to have significant or meaningful findings. Although all client participants attended Treatment Mall groups, it is unknown the quality of content of the provided groups or the level of client participation and involvement in the group process. A strength of the study is that it is a step in developing evaluation research on the Treatment Mall. To date, only one previous study (Longo, Marsh-Williams, \& Tate, 2002) included an aspect of evaluation on Treatment Mall outcomes. This is astounding, especially considering its 
widespread utilization in state psychiatric hospitals in over half of the states in the United States (Google search on "treatment mall", 2013).

Treatment Malls have been and are being implemented in many state hospitals across the country; however,

literature evaluating its effectiveness has been slow in coming. More research evaluating the effectiveness of Treatment Mall outcomes is needed, especially long term program evaluations and studies which compare Treatment Mall outcomes with other psychosocial treatment programming.

\section{REFERENCES}

Ballard, F. (2008). Benefits of psychosocial rehabilitation programming in a treatment mall. Journal of Psychosocial Nursing \& Mental Health Services, 46(2), 27-32.

Bartholomew T. \& Cook, R. (2013). Toward a fidelity scale for inpatient treatment malls. American Journal of Psychiatric Rehabilitation, 16, 179-197.

Bopp, J.H., Ribble, D.J., Cassidy, J.J., \& Markoff, R.A. (1996) Re-engineering the state hospital to promote rehabilitation and recovery. Psychiatric Services, 47(7), 697-701.

Boyer, C. A., McAlpine, D. D., Pottick, K. J., \& Olfson, M. (2000). Identifying risk factors and key strategies in linkage to outpatient psychiatric care. The American Journal of Psychiatry, 157(10), 1592-1598.

Brekke, J.S., Ansel, M., Long, J., Slade, E., \& Weinstein, M. (1999). Intensity and continuity of services and functional outcomes in the rehabilitation of persons with schizophrenia. Psychiatric Services, 50(2), 248256.

Carpenter, J. (2002). Mental health recovery paradigm: Implications for social work. Health and Social Work, 27(2), 86-94.

Chinman, M.J., Rosenheck, R., \& Lam, J.A. (2000). The case management relationship and outcomes of homeless persons with serious mental illness. Psychiatric Services, 51(9), 1142-1147.

Chow, W. S., \& Priebe, S. (2013). Understanding psychiatric institutionalization: A conceptual review. BMC Psychiatry, 13doi:10.1186/1471-244X-13-169

Coleman, J.C. \& Paul, G.L. (2001). Relationship between staffing ratios and effectiveness of inpatient psychiatric units. Psychiatric Services, 52(10), 1374-1379.

Dhillon, A.S \& Dollieslager, L.P. (2000). Overcoming barriers to individualized psychosocial rehabilitation in an acute treatment unit of a state hospital. Psychiatric Services, 51(3), 313-319.

Dietzen, L.L. \& Bond, G.R. (1993). Relationship between case manager contact and outcome for frequently psychiatric clients. Hospital and Community Psychiatry, 44, 839-843.

Langdon, P. E., Yágüez, L., Brown, J., \& Hope, A. (2001). Who walks through the revolving door' of a British psychiatric hospital? Journal of Mental Health, 10(5), 525-533.

Longo, A.M. Marsh-Williams, K., \& Tate, F. (2002). Psychosocial rehabilitation in a public psychiatric hospital. Psychiatric Quarterly, 73(3), 205-215.

Marsh-Williams, K. (2000). A rehabilitation program for inpatients in a large institution: The psychosocial rehabilitation program at eastern state hospital, Williamsburg, Virginia. Psychiatric Services, 51(11), 14421443.

Olfson, M., Mechanic, D., Hansell, S., Boyer, C.A., Walkup, J., \& Weiden, P.J. (2000). Predicting medication noncompliance after hospital discharge among patients with schizophrenia. Psychiatric Services, 51(2), 216-222.

Ragins, M., \& Pollack, D. (2013) Recovery and community mental health. In K. Yeager, D. Cutler, D. Svendsen, \& G.M. Sills (Eds.), Modern Community Mental Health: An Interdisciplinary Approach (pp. 385-404). New York, NY: Oxford University Press.

SAMHSA (2012). SAMHSA's working definition of recovery updated. Retrieved from http://blog.samhsa.gov/2012/03/23/defintion-of-recovery-updated/

Sands, R.G. \& Cnaan, R.A. (1994). Two modes of case management: Assessing their impact. Community Mental Health Journal, 30, 441-457.

Snowden, L.R. \& Clancy, R. (1990). Service intensity and client improvement at a predominantly black community mental health center. Evaluation and Program Planning, 13, 205-210.

Stromwall, L.K. \& Hurdle, D.E. (2003) Psychiatric rehabilitation: An empowerment- based approach to mental health services. Health and Social Work, 28, 206-213. 
Thorn, S.H., Bamburg, J.W., \& Pittman, A. (2007) Psychosocial Treatment Malls for people with intellectual disabilities. Research in Developmental Disabilities, 28, 531-538.

Vigod, S. N., Kurdyak, P. A., Dennis, C., Leszcz, T., Taylor, V. H., Blumberger, D. M., \& Seitz, D. P. (2013). Transitional interventions to reduce early psychiatric readmissions in adults: Systematic review. The British Journal of Psychiatry, 202(3), 187-194.

Webster, S.L. Div, M. Sheitman, B.B. Barboriak, P.N. Harmon, S.H. Paesler, B.T. Gordon, P.A. Kelly, S.K. \& Geller, J.L. (2009). Integrating Forensically and Civilly Committed Adult Inpatients in a Treatment Mall Program at a State Hospital. Psychiatric Services, 60, 262-265. 


\section{APPENDIX}

Table 1. Demographic Characteristics of Study Participants

\begin{tabular}{lcc}
\hline \multicolumn{1}{c}{$\mathbf{N = 6 7}$} & Mean/Frequency & SD/Percent \\
\hline Client Age (years) & 34 & 9 \\
Staff Age (years) & 47 & 10 \\
Administrator Age (years) & 52 & 6 \\
Client Length of Stay (months) & 6.2 & 9.3 \\
Employment Tenure of Staff (years) & 13.6 & 9.8 \\
Tenure of Administrators (years) & 19.6 & 11.3 \\
Sex of Clients (females) & 13 & $48 \%$ \\
Sex of Staff (females) & 20 & $67 \%$ \\
Sex of Administrators (females) & 2 & $33 \%$ \\
\hline
\end{tabular}

Table 2. Means and Standard Deviations of Survey Questions by Participant Group

\begin{tabular}{|c|c|c|c|c|}
\hline Survey Item & Admin & Staff & Clients & p-value \\
\hline $\begin{array}{l}\text { 1.) I have a voice in making decisions about my } \\
\text { treatment. }\end{array}$ & $4.3(2.0)$ & $5.1(1.5)$ & $5.0(2.1)$ & 0.61 \\
\hline $\begin{array}{l}\text { 2.) Members of my treatment team should treat } \\
\text { me/clients as a team member. }\end{array}$ & $6.7(0.5)$ & $4.8(1.4)$ & $5.0(1.9)$ & $0.04 *$ \\
\hline $\begin{array}{l}\text { 3.) My/clients individual needs are considered when } \\
\text { treatment services are offered to me. }\end{array}$ & 4.5 (1.6) & $5.2(1.4)$ & $5.3(1.6)$ & 0.47 \\
\hline $\begin{array}{l}\text { 4.) I/clients have learned useful skills by coming to } \\
\text { the Treatment Mall. }\end{array}$ & $5.0(0.6)$ & $5.8(1.3)$ & $5.6(1.7)$ & 0.51 \\
\hline $\begin{array}{l}\text { 5.) I/clients have become a more independent person } \\
\text { by coming to the Treatment Mall. }\end{array}$ & $5.0(0.9)$ & $5.5(1.3)$ & $5.2(2.1)$ & 0.63 \\
\hline $\begin{array}{l}\text { 6.) The Treatment Mall services will help me/clients } \\
\text { remain in my community after my discharge. }\end{array}$ & $5.5(1.0)$ & $5.0(1.7)$ & $5.2(2.0)$ & 0.81 \\
\hline $\begin{array}{l}\text { 7.) The Treatment Mall is helping me/clients in my } \\
\text { recovery. }\end{array}$ & $5.8(0.7)$ & $5.7(1.2)$ & $5.5(1.8)$ & 0.84 \\
\hline $\begin{array}{l}\text { 8.) I/clients am satisfied with what I am learning } \\
\text { through the Treatment Mall. }\end{array}$ & $6.7(0.5)$ & $6.8(0.5)$ & $5.0(2.0)$ & $0.00 *$ \\
\hline $\begin{array}{l}\text { 9.) I/ clients am satisfied with how I am treated at the } \\
\text { Treatment Mall. }\end{array}$ & $5.9(1.9)$ & $5.4(1.1)$ & $5.5(1.9)$ & 0.80 \\
\hline
\end{tabular}

Responses to questions were coded 1=strongly disagree, 2=disagree, 3=disagree somewhat, 4=neither or agree or disagree, $5=$ agree somewhat, $6=$ agree, $7=$ strongly agree

Table 3. Archival Data Performance Indicators ( $\mathrm{N}=183)$

\begin{tabular}{lccc}
\hline \multicolumn{1}{c}{ N (\%) } & Pre & Post & p-value \\
\hline PRN Hypnotic & $12(7)$ & $15(8)$ & .690 \\
PRN Anti-Psychotic & $25(14)$ & $22(12)$ & .728 \\
PRN Pain & $89(49)$ & $80(44)$ & .435 \\
PRN Benzodiazepine & $26(14)$ & $18(10)$ & .243 \\
Assault Client to Client & $4(2)$ & $6(3)$ & .727 \\
Assault Client to Staff & $5(3)$ & $1(1)$ & .125 \\
Elopements & $1(1)$ & $4(2)$ & .375 \\
Seclusions & $13(7)$ & $11(6)$ & .804 \\
Restraints & $8(5)$ & $4(3)$ & .508 \\
\hline
\end{tabular}

